psychological symptoms to their general practitioners and that consequently, opportunities for prevention and early diagnosis are being missed. This is demonstrated in the surveys described by Vize \& Priest. (Psychiatric Bulletin, 1993, 17, 573-574). As a profession we have made a working hypothesis that this represents a transference phenomenon related to patients' beliefs and attitudes about mental illness, and have predicted that health education will help to overcome their barrier to early intervention. We have also advocated screening in primary care settings, which as doctor-initiated consultations may depersonalise sensitive issues and remove the individual threat which inhibits patients from seeking help. Psychiatrists, however, continue to debate the diagnostic value of rating scales (Snaith, 1993), and I fear that many GPs remain unconvinced about the value of using such instruments during health checks.

An example of this is the assessment of the mental state of over-75-year-olds during annual health checks which were introduced as part of the GP contract in 1990 . There is wide variation in the organisation and content of these checks, but where mental state is assessed by rating instruments, up to $30 \%$ of patients have significant symptoms (Iliffe et al, 1991).

I have recently surveyed the content of over-75 health checks in 30 randomly selected GP practices in Norfolk. Twenty-three $(77 \%)$ responded, of which only one $(4.3 \%)$ routinely used a depression rating scale and only three (13.0\%) a scale assessing cognitive function. Thirteen practices (56.5\%) based their assessments on a general impression without any specific questioning; $70 \%$ of health checks were performed by nurses and health visitors.

Opportunities for prevention and early diagnosis are being missed. While in some cases there may be resource or training deficits, it seems likely that the case for screening has not been proven sufficiently to establish the priority for service provision. Shepherd (1991) highlighted the need for research and co-operation between GPs and psychiatrists. The paradigm and numbers needed to clarify issues of interpreting rating scales and their application as screening instruments in primary care lies exactly there, in general practice, where the story of depression usually begins and ends.

IlfFFe, S., Haines, A., Gallivan, S., Booroff, A. et al (1991) Assessment of elderly people in general practice. 1. Social circumstances and mental state. British Journal of General Practice, 41, 9-12.

SHEPHERD, M. (1991) Primary care psychiatry: the case for action. British Journal of General Practice, 41, 252-255.

SNATT, P. (1993) What do depression rating scales measure? British Journal of Psychiatry, 163, 293-298.

Michael, J. Noble, Little Plumstead Centre, Norwich NR13 5EW

\section{Italian mental health law}

Sir: Dr Rollin's article, ‘Community Care: Italy's "U" Turn' (Psychiatric Bulletin, 17, 494-495, 1993) reminded me of my recent study tour of the Fiorenzuola and Lombardy regions in Northern Italy. I realise that this limits my perspective and I will refrain from generalising too much. Jones (1991) argues that it is impossible to generalise about 'The Italian Experience'. Services in one district can be quite different from those in the next.

I heartily agree with Dr Rollin. The hospitality I experienced was excellent.

The principal goals of Law 180/78 included creating a decentralised community service of preventing mental illness and treating and rehabilitating mental patients and promoting comprehensive treatment, particularly through services outside a hospital framework (Cassana et al, 1985).

Law 180/78 actually succeeded in introducing significant change in the provision of psychiatric care. The emphasis has shifted from protection of the public towards better meeting of patients' needs through community care. New admissions to the 'old style' psychiatric hospitals ceased immediately. The law required re-admissions to cease without two years. Nobody was discharged 'willy-nilly' into the community. Psychiatrically ill patients are still admitted, mostly to 15 bed diagnosis and care units in general hospitals. The total number of admissions to these units was 54,104 in 1984; 79\% were voluntary admissions (Crepet, 1990).

But I do agree with Dr Rollin that there is a lesson for Mrs Bottomley. Professor Franco Rotelli has agreed that Law 180 falled because the political will never existed to implement it (Endean, 1993). But of even greater relevance to our own NHS, Signora Basaglia, (Franco Basaglia's widow) has consistently blamed the failure of law 180 on lack of resources.

I sincerely hope that the lessons for the Italian Experience becomes mandatory reading for those charged with implementing community care in the UK.

Cassano, G.B., Mauri, M. \& Petracca, A. (1985) The current status of psychiatric care in Italy. International Journal of Mental Health. 14, 174-183.

CREPET, P. (1990) A transition period in psychiatric care in Italy ten years after the reform. British Journal of Psychiatry. 156, 27-36.

ENDEAN, C. (1993) Italy retreats from community care for mentally ill. British Medical Journal, 306, 605.

JONES. K. (1991) The Italian Mental Health Law. British Journal of Psychiatry, 159, 556-557.

O. JUNAID, Queen's Medical Centre, University Hospital, Nottingham NG7 2UH 